\title{
S. M. Barr's Modern Physics and Ancient Faith: Are the Universe, Physical Law and Human Thought Proofs of God's Existence?
}

\author{
Egbert Giles Leigh Jr
}

Keywords: Animal minds; Abstracting; Consciousness; Cosmology; Mind and matter; Morality; Natural theology

\section{Modern Physics and Ancient Faith, by Stephen M. Barr. Notre Dame, Indiana: Notre Dame University Press. 2003. Reprinted 2011. Pp. xii + 313. P/b \$20.00, ISBN 0-268-02198-8}

Stephen Barr is an elementary particle physicist familiar with cosmology, who argues God's existence from two different sources of scientific evidence. He argues first from cosmology, then from the purported immateriality of the human mind. This book should interest this journal's readers because 1. Barr's cosmological argument, although no 'clincher', is perfectly reasonable. One can therefore assess the appropriateness of arguing God from design in a context that has not been poisoned by a willful, unreasonable hostility to Darwin's concept of evolution by natural selection, whereas 2. Barr's argument for God from the immateriality of mind is shaped by teachings of the Roman Catholic magisterium developed in defiance of, and intended to override, scientific enquiry. Barr's argument illustrates how these teachings, which exaggerate the (obvious) contrasts between human beings and other animals by denying minds to the latter, have detrimental consequences for scientific understanding, medical research and Christian behavior.

First, let us consider Barr's cosmological argument. I am a Christian imbued with Karl Barth's suspicion of 'natural theology' (the inference from nature of God's existence and attributes). I welcome arguments showing that belief in God is reasonable, a view many atheist voices deny, but I think the search for 'clinching' arguments for God that 'disprove' atheism do Christianity no service. God is said to want our love. Genuine love is a free choice (Bernanos 1953, pp. 273-274: see Leigh 2013), not the fruit of coercive

Correspondence: bufotyphonius@gmail.com

Smithsonian Tropical Research Institute, Apartado 0843-03092, Balboa Ancon, Panama, Republic of Panama proofs. I feel that Pascal's (1976) Pensée \#248 (my translation) was far closer to the truth in saying 'Faith is different from proof: the one is human, the other is a gift of God. "The just shall live by faith": that is the faith that God himself plants in one's heart. Proof is often his means of doing so, "faith comes by hearing," but this faith is in one's heart, and makes one say not "I know" but "I believe."

Barr observes that our universe began from a 'big bang,' and that some atheists took long to accept this fact. In accord with the Second Law of Thermodynamics, he argues that order must come from greater order, and asks where this order came from, as if thinking of the Prime Mover of Aristotle and St. Thomas Aquinas (Summa Contra Gentiles, Book I, chapter 13, article 3). He considers the beauty of physical law and 'the unreasonable effectiveness of mathematics in the natural sciences' (Wigner 1967) signs that a God, who wanted us to understand this order, created it. Sadly, Barr's appreciation of the beauty of physical law is not widely shared, because our age has failed so dismally to spread an understanding of the mathematics on which these laws are based. This failure has sharpened our society's divisions in various ways.

Next, Barr shows that for the universe to last long enough, generate enough different chemical elements, and grow large enough for some part of it to support the origin and evolution of life, the laws and constants of nature must be adjusted quite precisely. Indeed, Smolin (1992) thinks it can be shown that slight random changes in the constants of nature are overwhelmingly likely to diminish a universe's prospective lifetime and the number and size range of the stars it produces, a circumstance that suggests that our universe is organized to evolve life; cf Leigh and Vermeij, 2002. Barr's argument from these data that God created a universe where human beings would evolve is not coercive, 
as he recognizes. After all, were the universe otherwise, we would not be here to know it. Does his argument suffice to show that belief in God does not demand a flight from reason?

If valid, Barr's cosmological argument buys him little. One reason why Pascal (1976), Pensée \#556, p. 206, refused to try to prove the existence of God, the immortality of the soul and the like by natural reason was that 'this knowledge, without Jesus Christ, is useless and sterile.' And indeed, the philosophically inclined mathematical physicist Hermann Weyl, who had an unmatched sense of the beauty of mathematical law in physics (Weyl 1950, 1952), defined God as the 'completed infinite, who cannot penetrate into man by revelation, nor man penetrate to him by mystical perception' (Weyl 1932, p. 84). This is not the God of Abraham who hears, and can answer, prayer.

Nevertheless, the cosmological argument from design holds together far better than its biological counterpart. In The Expression of the Emotions in Man and Animals, Darwin (1872, p. 12) wrote 'as long as man and all other animals are viewed as independent creations, an effectual stop is put to our natural desire to investigate the causes of Expression. By this doctrine [of special creation] anything and everything could be equally well explained; and [this doctrine] has proved as pernicious with respect to Expression as to any other branch of natural history.' As Dobzhansky famously said, 'Nothing in biology makes sense except in the light of evolution, - - indeed, of evolution by natural selection. A cosmologist, however, might conclude that his knowledge of the universe and its laws makes the most sense if Someone created the universe who meant us to understand it. True, the reversal from the biological argument from design is incomplete. Unlike natural selection, God's actions escape experimental analysis, justifying St. Thomas's (Summa Theologica, Part I, Question 84, Article 1) exclusion from natural science of phenomena involving God's direct intervention. The example of Paley's (1803) natural theology, moreover, reminds us that new developments in science could overturn cosmological arguments for God in the twinkling of an eye. At the moment, however, the cosmological argument from design lacks the devastating alternatives that make its biological counterpart so implausible.

Many are now seeking alternatives for this cosmological argument. They believe, with Monod (1970, p. 37) and Smolin (1992, p. 774) that objective science cannot accept any explanation based on final causes or ultimate purposes as conveying genuine understanding. After all, discarding final causes from physical science, and focusing on how rather than why things happen, triggered the scientific revolution. In biology, however, it is as important to know why as how animals and plants do what they do and are designed as they are (Dennett 1995). Before Darwin, many saw this circumstance as proof that organisms were designed by God (Paley 1803): some still cling to this 'proof.' Nonetheless, when the assertion that the universe was designed to allow life to evolve attracted adherents, physicists sought mechanistic explanations of this circumstance to preserve the integrity of their science. Accordingly, Smolin (1992) devised an imaginative model of natural selection among universes that would eventually produce universes where life could evolve. Here, each gravitational collapse of a universe, and each new black hole, spawns a new universe with slightly different physical constants, and natural selection favors universes with new and larger stars, more of which eventually collapse into black holes - which universes are, incidentally, more propitious for evolving life. Dennett (1995) and Barr both review other ways used to circumvent the argument from design, involving unheard-of abundances of invisible universes that seem eminently ripe for Occam's razor. If the argument for God from cosmological design provokes such responses from its opponents, will it provoke others to view belief in God as reasonable enough to consider?

This book's second half - its Part V, What is Man? argues that some aspects of the human mind cannot be material. These aspects would be signs of God's direct action, and beyond the reach of science. He does not consider his argument absolutely coercive, but what he lists as its only alternatives are decidedly unappealing and implausible. Are these the only valid alternatives? Will his argument suffice to force quondam materialists into the corral of belief in God, in the intellectual equivalent of a cattle drive?

The materiality of minds, human or otherwise, however, is a biological problem. Barr is a physicist who seems unfamiliar with the relevant biological literature. He opens Part V by contrasting the 'materialist' view of human beings with the religious view promoted by the Roman Catholic magisterium - drawing a contrast between materialist monism and spiritualist dualism which the moral philosopher Paul Ricoeur finds abusively simplistic (Changeux and Ricoeur 1998). My central problem with this approach is the exaggeration of the contrast between human beings and other animals by attributing consciousness and thought only to human beings. In Barr's view, when a material human sperm fertilizes an equally material egg, God specially creates a soul for it (p. 225). Barr thinks that: 1 . in bodily function, humans are animals, 2 . there is a close connection between physical events in the brain and mental phenomena, and 3. the brain may be essential for any mental function. Nonetheless, his belief in a human soul leads him to insist that human intellect, free will and foresight (unlike the mental capacities of any other animal) cannot 'be entirely reduced to the material' (p. 173). We shall see how this doctrinally imposed dichotomy between human beings and other animals poisons his argument.

Barr then marshals his argument, in a series of deep questions with no clear answers: 
1. Do we have free will, the ability to make rational choices? Could this be true of purely material beings?

2. Can purely material beings understand? Can they know truth, factual or moral?

3. Does a human (or an animal) mind act like a computer?

One could respond to these questions as follows:

First, the indeterminacy of quantum mechanics may shatter the determinism of Newton's and Einstein's laws of physics (Barr, p. 179; Weyl 1949, p. 251). One could also argue that chaos places the hypothesis of determinism beyond the realm of testability. The ability of material beings to make rational choices accordingly hinges on the second question's answer.

Second, Barr argues that only human minds, with immaterial elements, can think, understand, and distinguish true from false. This argument fails because he distinguishes human beings too radically from other animals, and perhaps also because material beings can do things Barr says they cannot. Other animals cannot match human minds, which minds, indeed, have made human beings the de facto lords of Creation. Human minds, however, evolved by combining abilities already present in other animals as Konrad Lorenz (1977) showed.

Barr argues, for example, that only immaterial intellects can form abstract concepts. Nonetheless, many animals unconsciously, mechanistically, abstract persistent objects from a maze of sensory data derived from views of the object from different distances and angles, under different lighting (Lorenz 1977, pp. 117-120). Weyl (2009, p. 199) observes that the means by which physicists infer the presence of atoms or electrons are a natural prolongation of the operations a person's (or an animal's) 'mind performs (although mainly unconsciously) in perception, when, e.g., the solid shape of a body constitutes itself as the common source of its various perspective views.' The power to abstract objects from sensory data also allows animals to classify objects into categories, as do human babies (Lorenz 1977, p. 117).

Barr also restricts rational choice to human intellects. Rational choice requires thought and foresight. A tropical forest fruit bat has enough foresight to search for trees about to ripen fruit after eating its fill (Morrison 1978, p. 719). How widespread thinking is among animals is much disputed (Menzel and Fischer 2011), although it seems clear that some non-human animals do think. Darwin (1871, p. 48) recounts a friend's story of how his retriever solved a problem it had never previously encountered. This friend winged two ducks. The retriever, finding itself unable to bring back both at once, killed one something it had never done before - as if to prevent its escape, brought back the live duck, and returned to fetch the other. This solution required an ability to foresee the outcome of its actions. When faced with a problem, anthropoids, such as orangutans and chimpanzees, will act as if they are thinking through possible solutions, only acting after they have thought out an approach that suffices to solve the problem - choosing rationally among the alternatives they have thought of. Monkeys and raccoons, on the other hand, rush about, trying out each solution as it occurs to them (Lorenz 1977, pp. 127-128).

Moreover, many animals know truly (Lorenz 1977) and some can infer validly. From what a baboon sees and hears of the interactions among the other 80 members of its troop, it can infer the troop's dominance hierarchy (who takes precedence over whom) and matrilineal kinship relationships (who is whose mother, sister, brother, grandmother, etc.). Failure to get the dominance hierarchy right can earn the baboon a beating. Consistent failure to do so may cost it its reproductive success: natural selection favors a true grasp of the hierarchy. Moreover, some of these skills are transferable. South African Boers formerly used baboons as goatherds, partly because they had the ability to associate kids with their correct mothers that no human being could match (Cheney and Seyfarth 2007).

Barr also thinks that moral choices require immaterial intellects. Many animals, however, live in groups whose members can jointly accomplish what no member could do alone - warding off competitors or predators, sharing knowledge of where to find food, or taking down large prey. Group life is mutually advantageous only if cheating can be restrained sufficiently to preserve the benefits of cooperation. Insofar as all a group's members do, or will eventually, contribute to its effectiveness, it behooves each member not to endanger a fellow's welfare (Leigh 2010), just as a gang of thieves will only be effective if they treat each other justly and sympathetically (Plato, Republic I, 352c; Waley 1982, p. 74). Accordingly, relatively intelligent social mammals such as dogs, wolves, monkeys and chimpanzees show the rudiments of morality: they can act from empathy, cooperate toward common goals, and understand the rudiments of 'fair play' (Darwin 1871, pp. 69-106; Bekoff and Pierce 2009). These propensities are often most evident in young animals at play, which hones both their motor and their social skills (Bekoff and Pierce 2009). In non-human animals, such 'moral obligation' seldom extends beyond one's own group: surely, that circumstance is unconnected with materiality.

Third, Barr argues, quite correctly, that the human mind cannot be viewed as a computer. A traditional computer is a logical machine for drawing consequences from premises by symbol manipulation (McGinn 1999, pp. 179-180). The Viennese logician Kurt Gödel showed that one could formulate statements in terms of a self-consistent set of axioms which could not be proved from these axioms, which nonetheless were true (Nagel and Newman 2001): Barr, laudably, provides an outline of this proof. If these axioms and rules for deduction functioned as our brain's 
computer program, it could not know the truth of a statement that we recognize as true, so our brain cannot be a computer. Thinking beings, however, spend far more time using their minds which make hypotheses about their environs and test them empirically rather than deducing them logically from premises (Changeux and Ricoeur 1998, p. 56). Hofstader (2001, p. xvii) remarks that thinking beings use guesswork, analogy, and trial and error far more often than logical deduction. Must the minds that behave thus be partly immaterial?

Proper answers to Barr's question, however, hinge on understanding consciousness. Yet, we are no nearer to understanding consciousness now (McGinn 1999) than when Monod (1970, pp. 198-199) warned that we might have to wait long for an understanding of how our minds interact with our physical bodies. One can still say with Thompson (1942, p. 13) that 'Consciousness is not explained to my comprehension by all the nerve-paths and neurons of the physiologist.' We are still faced with Weyl's (1949, p. 215) riddle of the 'double position of the ego: it is not merely an existing individual which carries out real psychic acts but also 'vision', a self-penetrating light (sense-giving consciousness, knowledge, image, or however you may call it).' Like Monod (1970, pp. 198-199), Lorenz (1977, p. 169) remarks on the barrier, 'utterly impenetrable to the human understanding, that runs through the middle of what is the undeniable one-ness of our personality - the barrier that divides our subjective experience from the objective, verifiable physiological events that occur in our body.' Lorenz (1977, p. 170) considers this barrier unbridgeable, at least with the cognitive apparatus at our disposal and probably unbridgeable in principle. McGinn (1999, p. 51) comments on the subjective introspection-based view of consciousness' and the objective 'perception-based view of the brain, staring at each other across a yawning conceptual divide.'

Indeed, there is disagreement on how to define consciousness. Nagel (1974, p. 436) thinks of consciousness as (remembered?) 'conscious experience'; Lorenz (1977, pp. 169-170) thinks of it as our 'subjective experience,' our 'feelings'; McGinn (1999, pp. 2-3) considers it 'the having of sensations, emotions, feelings, thoughts.' McGinn (1999) does not consider consciousness the same as selfawareness. Monod (1970, pp. 198-199) on the other hand, thinks of our consciousness as the ability to simulate in our minds hypothetical actions or events and their consequences - in other words, our ability to imagine.

Monod's definition will not help us understand whether consciousness has a material basis, but it does enable us to learn that consciousness, whether material or not, is not restricted to human beings: many animals have it, and depend on it to live their lives. 'Dreams are just another form of consciousness' (McGinn 1999, p. 2). Darwin (1871, p. 46) quotes a phrase, 'dream is an involuntary art of poetry' and remarks that 'As dogs, cats, and probably all the higher animals. . . have vivid dreams [as] is shown by their movements and voice, we must admit that they possess some form of imagination.' The many animals that dream must have consciousness. As for the uses of consciousness, Lorenz (1977, p. 128) tells of an orangutan placed in a room with a box in one corner and a banana too high to reach in the opposite corner. He sat frustrated until he looked from the box to the floor under the banana and then to the banana itself. Then, as if he had just simulated in his mind moving the box under the banana and climbing the box to get it, he suddenly, delightedly, moved the box and got the banana. Even the way humans use consciousness reveals some analogy with our fellow animals. Weyl (1949, p. 283) remarks that his inner subjective selfawareness is the basis for his understanding of other people, and its illuminating light. . . also reaches, though with ever increasing dimness and incertitude, deeply into the animal kingdom.' That is why animal behaviorists understand their study animals better if they strive to see the world through their animals' eyes. Weyl's remark also explains why animal behaviorists so want to learn the extent to which their study animals try to infer what their fellow group members desire, intend or know (Cheney \& Seyfarth 2007).

In sum, whether consciousness and certain aspects of intellect have a partly immaterial basis is unknown, and may be unknowable (McGinn 1999). It is, however, becoming ever clearer that the material brain plays an essential role in every mental function. So I agree with Changeux and Ricoeur (1998) that it is legitimate to assume that with the phenomena of the brain no influence alien to physics and chemistry interferes. Such research has already amplified our understanding of our brains' relationship to other parts of our bodies, and it has had striking medical implications (Damasio 1994).

Barr's primary problem here is his dogmatic denial of consciousness, thought, foresight and the rudiments of morality to other animals. I do not understand why any Christian would want to declare such limits on God's generosity to His creatures: this is a heavy price to pay for winning an argument. Moreover, the denial of consciousness and foresight to cats, dogs, rats, even primates, and the concomitant assumption that they cannot feel pain as we do, has been used to justify inflicting cruel pain on animals (Midgley 1983; Griffin 2001, pp. 253-269). In fact, denying all animals these capacities - such a contrast with Darwin's extraordinary sympathy for animals - makes us less insightful, less sympathetic lords of Creation. Our lordship of creation is an inescapable fact, whatever our religion or lack of it. This lordship imposes duties that we must not shirk. Barr's Part V is an example of how uncritical adherence to arbitrary religious teachings leads not only to bad science but behavior that discredits belief in God. It is a sad conclusion to an otherwise well-balanced, constructive book. 


\section{Competing interest}

The author declares that he has no competing interests.

Received: 9 January 2014 Accepted: 13 February 2014 Published online: 09 April 2014

\section{References}

Bekoff, M, \& Pierce, J. (2009). Wild justice: the moral lives of animals. Chicago, IL: University of Chicago Press.

Bernanos, G. (1953). Nos amis les saints. In G Bernanos (Ed.), La liberté pour quoi faire? (pp. 261-289). Paris: Gallimard.

Changeux, J-P, \& Ricoeur, P. (1998). Ce qui nous fait penser: la nature et la règle. Paris: Odile Jacob.

Cheney, DL, \& Seyfarth, RM. (2007). Baboon metaphysics. Chicago, IL: University of Chicago Press.

Damasio, AR. (1994). Descartes' error: emotion, reason and the human brain. New York: G. P. Putnam's Sons.

Darwin, C. (1871). The descent of man, and selection in relation to sex. London: John Murray.

Darwin, C. (1872). The expression of the emotions in man and animals. London: John Murray.

Dennett, DC. (1995). Darwin's dangerous idea: evolution and the meanings of life. New York, NY: Simon and Schuster.

Griffin, DR. (2001). Animal minds: beyond cognition to consciousness. Chicago, IL: University of Chicago Press.

Hofstadter, DR. (2001). Forward. In E Nagel \& JR Newman (Eds.), Gödel's proof (pp. ix-xii). New York, NY: New York University Press.

Leigh, EG, Jr. (2010). The group selection controversy. Journal of Evolutionary Biology, 23(1), 6-19.

Leigh, EG, Jr. (2013). Does evolution compromise Christian faith? R. J. Asher's Evolution and Belief Evolution: Education and Outreach, 6, 15.

Leigh, EG, Jr, \& Vermeij, GJ. (2002). Does natural selection organize communities for high diversity and productivity? Philosophical Transactions of the Royal Society of London B, 357(1421), 709-718.

Lorenz, K. (1977). Behind the mirror. London: Methuen.

McGinn, C. (1999). The mysterious flame: conscious minds in a material world. New York, NY: Basic Books.

Menzel, R, \& Fischer, J (Eds.). (2011). Animal thinking: contemporary issues in comparative cognition. Cambridge, MA: MIT Press.

Midgley, M. (1983). Animals, and why they matter. Athens, GA: University of Georgia Press. Monod, J. (1970). Le hasard et la necessité. Paris: Éditions du Seuil.

Morrison, DW. (1978). Foraging strategy and bioenergetics of the frugivorous bat Artibeus jamaicensis. Ecology, 59(4), 716-723.

Nagel, E, \& Newman, JR. (2001). Gödel's proof, revised edition. New York, NY: New York University Press.

Nagel, T. (1974). What is it like to be a bat? Philosophical Review, 83(4), 435-450.

Paley, W. (1803). Natural theology: or, evidences of the existence and attributes of the deity, collected from the appearances of nature (5th ed.). London, England: Faulder.

Pascal, B. (1976). Pensées. Paris: Garnier-Flammarion.

Smolin, L. (1992). Did the universe evolve? Classical and Quantum Gravity, 9, 173-191.

Thompson, DW. (1942). On growth and form (2nd ed.). Ambridge, England: Cambridge University Press.

Waley, A. (1982). Three ways of thought in ancient China. Stanford, CA: Stanford University Press.

Weyl, H. (1932). The open world. New Haven, CT: Yale University Press.

Weyl, H. (1949). Philosophy of mathematics and natural science. Princeton, $\mathrm{NJ}$ : Princeton University Press.

Weyl, H. (1950). The theory of groups and quantum mechanics. New York, NY: Dover Press.
Weyl, H. (1952). Symmetry. Princeton, NJ: Princeton University Press.

Weyl, H. (2009). The unity of knowledge. In P Pesic (Ed.), Mind and nature (pp. 194-203). Princeton, NJ: Princeton University Press.

Wigner, EP. (1967). The unnatural effectiveness of mathematics in the natural sciences. In EP Wigner (Ed.), Symmetries and reflections (pp. 222-237). Bloomington, IN: Indiana University Press.

doi:10.1186/s12052-014-0008-1

Cite this article as: Leigh: S. M. Barr's Modern Physics and Ancient Faith: Are the Universe, Physical Law and Human Thought Proofs of God's Existence?. Evolution: Education and Outreach 2014 7:8.

\section{Submit your manuscript to a SpringerOpen ${ }^{\odot}$ journal and benefit from:}

- Convenient online submission

Rigorous peer review

- Immediate publication on acceptance

- Open access: articles freely available online

- High visibility within the field

- Retaining the copyright to your article

Submit your next manuscript at $>$ springeropen.com 